\title{
An Analysis of the Surface Geometric Structure and Geometric Accuracy of Cylindrical Gear Teeth Manufactured with the Direct Metal Laser Sintering (DMLS) Method
}

\author{
Jadwiga Małgorzata Pisula - Grzegorz Budzik - Łukasz Przeszłowski \\ Rzeszow University of Technology, The Faculty of Mechanical Engineering and Aeronautics, Poland
}

This paper presents findings concerning the accuracy of the geometry of cylindrical spur gear teeth manufactured with the direct metal laser sintering (DMLS) method. In addition, the results of the evaluation of the tooth surface geometric structure are presented in the form of selected two-dimensional and three-dimensional surface roughness parameters. An analysis of the accuracy of the fabricated gear teeth was performed after gear sand-blasting and gear tooth milling processes. Surface roughness was measured before and after sand-blasting and gear tooth milling. The test gear wheel was manufactured from GP1 high-chromium stainless steel on an EOS M270 machine.

Keywords: direct metal laser sintering (DMLS) method, surface geometric structure, cylindrical spur gears, geometric accuracy

Highlights

- An analysis of the geometric accuracy of a cylindrical spur gear made with the additive DMLS method allows us to appropriately select assumptions for the finishing process using cutting machining techniques.

- $\quad$ Sandblasting does improve the geometric structure of the surface of the gear, and the results comply with the manufacturer's data.

- $\quad$ The geometric structure of the gear tooth surface after the milling process using a universal tool is better than given in the manufacturer's data.

- $\quad$ The accuracy of a cylindrical spur gear fabricated by means of DMLS from GP1 material is classified outside accuracy class 12.

- $\quad$ Sandblasting does not improve the accuracy of gear teeth.

- The application of a universal tool for gear tooth machining of gears manufactured by DMLS reaches accuracy class 8 according to DIN 3962-1,2.

- Cylindrical spur gears made with the additive DMLS method and subjected to cutting machining may be used in single-piece and small-volume production.

\section{INTRODUCTION}

The interest in three-dimensional (3D) printing of metallic material is constantly growing. Competition between various manufacturers and suppliers of machines using additive techniques encourages them to offer increasingly improved and more automated products, which inspires the search for new technologies. In addition, printing offers new geometric possibilities in terms of the design of the parts. Fabricating inner cooling channels of continuous design, openwork patterns or honeycomb structures has become a reality. The aircraft industry is already implementing such technologies, closely followed by the automotive sector [1].

The direct metal laser sintering (DMLS) method is an additive technology of fabricating parts from metal and a practical alternative to components manufactured by casting. Shorter single-piece or smallvolume manufacturing time is a benefit of fabricating a part on the basis of a 3D computer-aided design (CAD) model. In manufacturing, DMLS provides precise, functional, and durable parts. Interest in the technology is confirmed by publications concerning microstructures and the mechanical properties of molten material. For example, in the papers [2] to [4], the results of experiments aimed at determining the mechanical properties of samples obtained with the DMLS method for various metallic powders are presented. In addition, works [3] and [4] investigated the impact of fabrication orientation, surface polishing upon mechanical behaviour of metallic alloys and their microstructural properties. In the paper [5], the microstructure and elemental composition stainless steel powder have been examined. In [6], the author studied the effect of processing parameters on the densification and microstructural evolution during direct laser sintering of metal powders. The sintering process and the resultant mechanical strength of nickel nanoparticles were studied in the paper [7] using molecular dynamics simulations. In work [8], the size and volume fraction of SiCp have been varied to analyse the crack and wear behaviour of the Al-based composite. Only in some studies do we find guidelines 
on the selection of parameters of the melting process and their effect on the properties of the final product. The paper [9] describes how an optical in-process monitoring system for DMLS process can be set up and used for purposes of understanding the process and quality assurance. In work [10], the authors optimized the process parameters, such as the laser scan rate and scanning pattern, to obtain high-density parts of multicomponent iron base powder blend. In work [11], important parameters and restrictions in the production of customized titanium implants are described. Such publications rarely contain any information on designing parts fabricated with the DMLS method or the evaluation of the usefulness of printed parts. In work [12], how to manufacture isoelastic dental implant materials with optimized surface properties is reported, and in [13] how to provide complete control over the microarchitecture of porous titanium implants is described.

Depending on the application, gear transmissions should be characterized by suitable geometric and kinematic accuracy, as well as durability [14]. The structure of DLMS-fabricated gears is porous, which enables their impregnation by grease or the application of a layer improving the gear's strength [14]. This provides increased gear wear resistance and prevents excessive friction heating. In the present study, a set of cylindrical spur gears was made using the DMLS method. The gears were subsequently subjected to final cutting machining to produce an entirely adequate product. Next, the geometric accuracy of the gears was measured on a P40 by Klingelnberg coordinate measuring machine, and the geometric structure of the tooth surface at selected stages of the manufacturing process was analysed.

\section{METHOD}

\subsection{The DMLS Method}

DMLS (a registered trademark of EOS $\mathrm{GmbH}$ ) is based on the laser beam melting (LBM) technology, a technique classified as power bed fusion process. Although the name DMLS contains the word 'sintering', this additive fabrication process uses a laser beam to fully melt metal particles [15]. Selective laser melting (SLM) is a more appropriate term for this process, but the name is a registered trademark of SLM Solutions. In the case under consideration, the EOS M270 machine uses Yb-fibre lasers. This type of laser provides an exceptionally high beam quality combined with performance stability [16]. The material is collected from a container and subsequently applied in the workspace in layers by means of a scraper. The thickness of the applied layer depends on the type of material in the container and may vary in the range from $0.01 \mathrm{~mm}$ to $0.08 \mathrm{~mm}$. As the metal is fused, certain melting irregularities occur, which are removed by a blade attached to the scraper. Following the application of a particular layer of the material in the location of the fabricated model, a laser beam scans its geometry, fusing the metal across the respective sections of the model. After scanning the entire surface of a respective section of the model, the powder application and scanning process repeat in the entire powder bed. Correct model data processing and process simulation, which minimizes errors that may occur at the final stage of the additive process, play an essential role in the DMLS technique.

DMLS requires generating permanent anchoring structures due to the rapid contraction of metals after melting (due to a significant temperature difference between the atmosphere of the work chamber and molten metal). In this case, anchors prevent the metallic material from bending upwards due to a shrinkage caused by the material's phase transformations.

Materials commonly applied in the technique include aluminium, titanium, stainless steel, maraging steel, nickel alloys, and cobalt-chromium alloys [16].

\subsection{Test Models}

Test models were made on an EOS M270 machine on the basis of a 3D CAD-designed gear model, the profile of which was obtained by simulated machining [17]. Gear geometry parameters are included in Table 1. The choice of gear geometry was dictated by the dimensions of the EOS M270 machine's working die $(250 \mathrm{~mm} \times 250 \mathrm{~mm}$, on which 9 parts were evenly distributed) (see Fig. 1). A small, odd number of gear teeth $(z=19)$ was intended to prevent tooth undercut and the presence of the gear to relevant axial planes.

Table 1. Basic geometric data of the gear model

\begin{tabular}{lc}
\hline Designation & Quantity \\
\hline Number of teeth $z$ & 19 \\
\hline Normal module $m_{n}$ & $3.0 \mathrm{~mm}$ \\
\hline Profile angle $\alpha_{n}$ & $20 \mathrm{deg}$ \\
\hline Helix angle $\beta$ & $0.0 \mathrm{deg}$ \\
\hline Profile modification coefficient $x$ & 0.0 \\
\hline Clearance $c$ & $0.75 \mathrm{~mm}$ \\
\hline Whole depth $h$ & $6.75 \mathrm{~mm}$ \\
\hline Face width $b$ & $10.0 \mathrm{~mm}$ \\
\hline
\end{tabular}


Gears were modelled in several variants of allowance thickness, which resulted from the assumed technological process of gears and compensation for material shrinkage. Prior to melting, pre-production was performed, involving the use of the specialist software EOSTATE Magics RP by Materialise. This stage included preparing the model for the process and setting up the machine according to the manufacturer's recommendations. The preparation of the model included data processing (creating an .stl file of specific accuracy), determining the model's suitable location in the workspace and designing appropriate anchors.

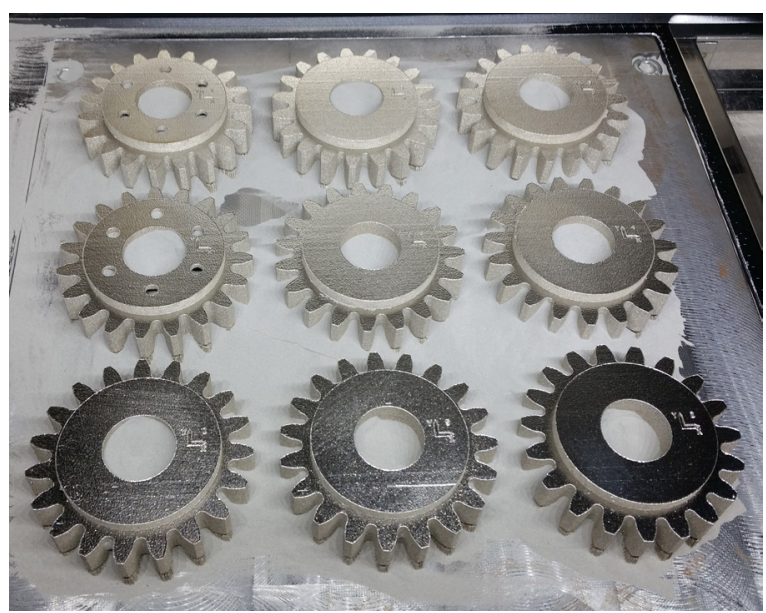

Fig. 1. A set of gears on the building platform after the melting process using the DMLS method

Fig. 1 shows the gears after additive manufacturing. They are characterized by specific orientation with respect to each other and the machine's coordinate system. The assumed location of the gears on the building platform in the horizontal position resulted in a uniform structure of the gear's transverse plane, which is impossible when the gears are positioned vertically (which undoubtedly leads to tooth strength and stress variation along the circumference). In addition, in the case of vertical gear alignment, tooth geometry mapping on the circumference of the gear is uneven, and problems with post-processing arise. The use of special part marks made it possible, for example,. to carry out an analysis of the accuracy of model mapping depending on the machine's scraper location. Moreover, it enables testing the relationship between tooth strength and tooth location on the work platform as well as the parameters of the stress-relief process.

The EOS StainlessSteel GP1 material used for fabricating the gears consists of high-chromium stainless steel, the chemical composition of which complies with standard PN-EN-10027-2 steel 1.4542 [18]. GP1 steel is characterized by good mechanical properties, in particular, excellent ductility. The material is used in DMLS primarily for making functional prototypes of metal parts and finished products in single-piece and small-volume production, as well as for medical purposes. Parts made of GP1 stainless steel can be machined, welded, beadblasted (sand-blasted), and polished; spark erosion and coating may also be applied [16]. Regarding the gear wheels, the material GP1 is used mainly in the chemical industry due to its anti-corrosive and selflubricating properties, e.g., in gear pumps [19] and in drive systems of radial flow sedimentation tanks [20]. In this study, the smallest possible layer thickness in the processing of GP1 was $0.02 \mathrm{~mm}$. The duration of the process depends on the number of layers applied and the size of the area which must be irradiated with a laser beam when fusing the subsequent layer. For the printed gear (as the semi-finished product with a pre-determined profile) the process lasted $9 \mathrm{~h} 34 \mathrm{~min}$ (see Fig. 2a). Important information on the process of fusing the gear model is shown in Table 2 .

a)

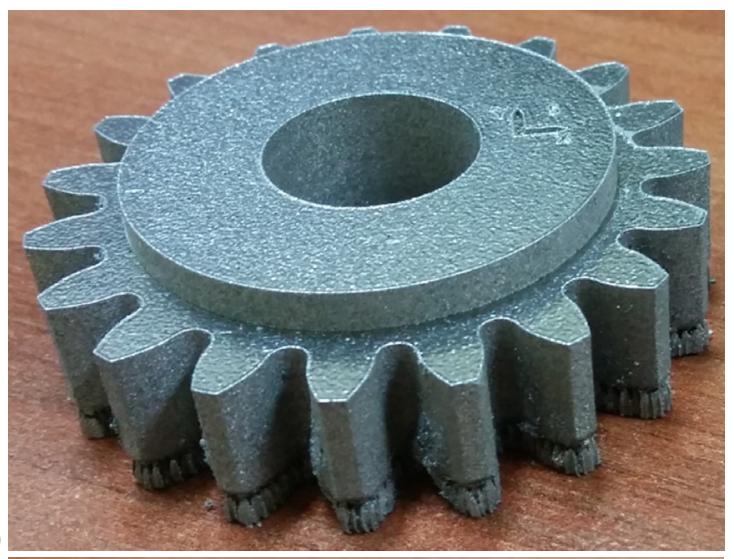

b)

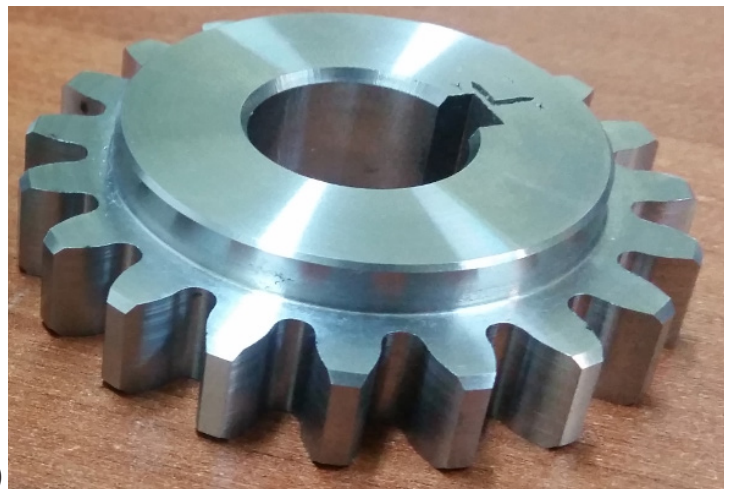

Fig. 2. A test gear fabricated using the DMLS technology; a) after the melting process and after stress-relieving, and b) after the complete machining process 
Table 2. Parameters used in melting the gear model (DMLS)

\begin{tabular}{ll}
\hline Printer & EOSINT M270 \\
\hline Accuracy $(p=99.7 \%)$ & $\begin{array}{l}\text { Parts are produced with the accuracy of } \\
\pm 20 \mu \mathrm{m}-50 \mu \mathrm{m}[16]\end{array}$ \\
\hline Material & GP1 \\
\hline Software & EOSTATE Magics RP by Materialise \\
\hline Layer thickness & $0.02 \mathrm{~mm}$ \\
\hline Manufacturing time & $9 \mathrm{~h} 34 \mathrm{~min}$ \\
\hline
\end{tabular}

After the additive manufacturing process, the post-processing stage begins. Apart from stressrelieving (to eliminate internal stress) and cutting the model off the building platform (by band-saw), postprocessing included machining (dismantling anchors, machining datum planes and other surfaces, as well as tooth milling). A $3 \mathrm{~mm}$ shank-type end mill [21] was used in the gear tooth final milling process as a machining tool. The gear teeth machining process involved the application of contour milling, i.e., the cutting edges, placed on the cylindrical surface of the tool, was moving on the tooth gap profile of the gear defined directly in the CAD model. The entire removal machining process was performed on a $\mathrm{CNC}$ turning centre (ST-20Y by Haas). The parameters of the gear tooth milling process are shown in Table 3. The duration of the final machining was $4.1 \mathrm{~min}$. In comparison, rough milling from a solid block in the gear lasted $41.05 \mathrm{~min}$.

Table 3. Parameters used in the machining process (Gear teeth milling process)

\begin{tabular}{ll}
\hline Cutter machine & CNC turning centre ST-20Y by Haas \\
\hline Tool & $\begin{array}{l}\text { end mill VHM VHTS } \phi 3.0 \mathrm{~mm} \times 6 \mathrm{~mm} \times \\
10 \mathrm{~mm} \times 57 \mathrm{~mm}, 4 \text { flute (Van Horn) }\end{array}$ \\
\hline Material & GP1 (EOS StainlessSteel GP1) \\
\hline Cutting speed $V_{c}$ & $57.0 \mathrm{~m} \cdot \mathrm{min}^{-1}$ \\
\hline Feed per tooth $f n$ & $0.005 \mathrm{~mm} \cdot$ tooth $^{-1}$ \\
\hline Depth of cut $a p$ & $0.02 \mathrm{~mm}$ \\
\hline Spindle speed $n$ & $6000 \mathrm{rpm}$ \\
\hline $\begin{array}{l}\text { Duration of the final } \\
\text { machining }\end{array}$ & $4.1 \mathrm{~min}$ \\
\hline
\end{tabular}

Some gears were sand-blasted to evaluate the suitability of the process in terms of tooth geometry and surface geometry structure. In the sandblasting process Brown Fused Alumina (BFA) grain F80 according to FEPA 42 D 1984 Teil 2 standard was used. A gear after a complete machining process is shown in Fig. 2b.

\subsection{Measurement of the Models}

Gear measurements at each stage of the manufacturing process were performed on a P40 coordinate measuring machine by Klingelnberg, which utilizes a contact method for measurements. In this method, geometric features of the test object are measured on the basis of a set of measurement points, acquired by the coordinate measuring machine (CMM) by means of contact (probing) heads, as well as scanning heads in a single coordinate system without the need to adjust the mounts fixing the object. Gear geometry and parameters characterizing the gear blank and the tooth geometry are acquired by means of special software for, respectively, axial-symmetrical elements and cylindrical gear measurements. The selected machine parameters P40 of the Klingelnberg used for gear measurements are presented in Table 4.

Table 4. Parameters used to measure the gears

\begin{tabular}{ll}
\hline Measuring machine & $\begin{array}{l}\text { Klingelnberg Gear Measuring } \\
\text { Centre P40 }\end{array}$ \\
\hline Probe System & K3D (M44) \\
\hline Resolution & $<0.01 \mathrm{~mm}$ \\
\hline Probe, head diameter & $1.5 \mathrm{~mm}$ \\
\hline Evaluation range $L \alpha$ for the profile & $7.0 \mathrm{~mm}$ \\
\hline Evaluation range $L \beta$ for the lead & $10.94 \mathrm{~mm}$ \\
\hline Length measurement uncertainty & $\begin{array}{l}\text { according to VDI } / \mathrm{VDE} 2617 \\
\mathrm{U} 1=18+\mathrm{L} / 250 \text { [mm] } \\
L=\text { length in mm }\end{array}$ \\
\hline Teeth to be checked (profile, lead) & $\begin{array}{l}3 \text { teeth (evenly around the gear } \\
\text { circumference) }\end{array}$ \\
\hline
\end{tabular}

The measurements were performed in order to determine the accuracy of cylindrical spur gears made by means of the DMLS technology. Gears were tested after melting, tooth sanding, and tooth milling. In each case, the same datum references were considered, i.e., the cylindrical surface and the end face.

An evaluation of the accuracy of the geometric surface structure of gear teeth fabricated using the DMLS technology at selected stages of the manufacturing process was performed. Tooth flank topography measurements were taken by means of the contact method using a Talyscan 150 3D scanning instrument with a sample spacing of $5 \mu \mathrm{m}$ in directions $\mathrm{X}$ and $\mathrm{Y}$, and a measuring needle with a rounding radius of $2 \mu \mathrm{m}$. Surface topographies were recorded for an area of $2.5 \mathrm{~mm}$ by $2.5 \mathrm{~mm}$ so that the centre was located at the intersection of the pitch diameter in mid-width of the toothed ring. The measurement was performed in 501 passes, with 501 points recorded 
in a single pass with the speed of $\mathrm{V}=2000 \mu \mathrm{m} / \mathrm{s}$. Measurement data processing and the calculation of the topographic parameters of the analysed surfaces were performed in TalyMap Expert and Mountains Map Universal applications by the company Taylor Hobson. Due to shape removal and levelling issues, the area selected for analysis was narrowed down.

\section{RESULTS AND DISCUSSION}

\subsection{An Analysis of the Accuracy of Teeth and the Datum Plane of the Gear}

For the gear tooth accuracy assessment, parameters characterizing the tooth geometry that define the gear accuracy class [22] and [19] are considered. Table 5 contains the results of gear tooth measurements, in which only the parameters defining tooth profile, tooth line, and pitch accuracy class were provided after melting and sand-blasting without datum reference machining.

Table 5. Accuracy classes with values of class-defining of parameters: after melting and sand-blasting without datum reference machining [22]

\begin{tabular}{cccc}
\hline & $\begin{array}{c}\text { Profile accuracy } \\
\text { class }\end{array}$ & $\begin{array}{c}\text { Tooth line } \\
\text { accuracy class }\end{array}$ & $\begin{array}{c}\text { Pitch accuracy } \\
\text { class }\end{array}$ \\
\hline $\begin{array}{c}\text { After } \\
\text { melting }\end{array}$ & $>>$ & $>>$ & 12 \\
& $f_{H \alpha}=-72.5 \mu \mathrm{m}$ & $f_{f \beta}=85.1 \mu \mathrm{m}$ & $f_{p \max }=50.5 \mu \mathrm{m}$ \\
& & & $f_{u \max }=91.7 \mu \mathrm{m}$ \\
\hline $\begin{array}{c}\text { After } \\
\text { sand- } \\
\text { blasting }\end{array}$ & $f_{H \alpha}=-73.3 \mu \mathrm{m}$ & $f_{H \beta}=48.1 \mu \mathrm{m}$ & $f_{\text {pmax }}=40.9 \mathrm{~mm}$ \\
& & $f_{f \beta}=34.5 \mu \mathrm{m}$ & $f_{u \max }=62.0 \mathrm{~mm}$ \\
\hline
\end{tabular}

Table 6. Accuracy classes together with class-defining parameters: before tooth machining and after milling with machined datum planes [22]

\begin{tabular}{cccc}
\hline & $\begin{array}{c}\text { Profile accuracy } \\
\text { class }\end{array}$ & $\begin{array}{c}\text { Tooth line } \\
\text { accuracy class }\end{array}$ & $\begin{array}{c}\text { Pitch accuracy } \\
\text { class }\end{array}$ \\
\hline $\begin{array}{c}\text { Before } \\
\text { tooth } \\
\text { machining } \\
\text { (after } \\
\text { melting) }\end{array}$ & $\begin{array}{c}12 \\
f_{H \alpha}=-62.9 \mathrm{~mm} \\
f_{\alpha}=82.2 \mathrm{~mm}\end{array}$ & $\begin{array}{c}>> \\
f_{f \beta}=63.0 \mathrm{~mm}\end{array}$ & 11 \\
\hline $\begin{array}{c}\text { After tooth } \\
\text { milling }\end{array}$ & 7 & 7 & $f_{\text {umax }}=47.9 \mathrm{~mm}$ \\
process & $f_{H \alpha}=7.3 \mathrm{~mm}$ & $f_{H \beta}=10.3 \mathrm{~mm}$ & $f_{\text {umax }}=12.8 \mathrm{~mm}$ \\
& & $f_{f \beta}=6.9 \mathrm{~mm}$ & \\
\hline
\end{tabular}

A gear subjected to the melting process is outside accuracy class 12, according to DIN 3962. The main reasons are high values of the tooth profile position deviation $\left(f_{H \alpha}\right)$ as well as large deviations of the tooth line position and shape $\left(f_{H \beta}, f_{f \beta}\right)$. Despite a pitch accuracy class of 12 (maximum values obtained for the maximum unit pitch deviation $f_{p \max }$ and the greatest pitch interval deviation $f_{\text {umax }}$ ), the gear class is determined by the results obtained from the tooth line and profile accuracy classes. Gear tooth accuracy after sanding is also outside the accuracy class due to the profile, whose position deviation $\left(f_{H \alpha}\right)$ is as high as after melting. Sanding does not affect the profile position but instead improves other ratings of the tooth profile $\left(f_{f \alpha}\right.$ is the tooth profile shape deviation and $F_{\alpha}$ the total profile deviation), i.e., by decreasing them. Sand-blasting enables only a slight improvement of the tooth line and the gear pitch, both of which attain accuracy class 11 .

For the second set of gears fabricated with the DMLS technology, datum surfaces were machined by turning. The datum surfaces were the cylindrical surface of the hole and the butting plane of the gear hub. This is the butting plane from which the supporting structures were cut off. To make the datum surfaces, the gears were mounted in a three-jaw chuck covering the cylindrical and abutting surface of the hub, which was designed for this purpose. Next, the teeth were milled. When measuring gear teeth, the same datum references as in the previous gear set (cylindrical surface and end face) were considered. The mean radial and axial runout values for the datum planes after turning are $0.0062 \mathrm{~mm}$ and $0.0093 \mathrm{~mm}$, respectively. Table 6 presents the results of gear teeth measurements, in which only the parameters determining tooth profile, tooth line and pitch accuracy class before tooth machining and after milling were provided.

Datum reference accuracy plays a vital role in tooth geometry measurements. A comparison of results from Tables 5 and 6 before tooth machining (after melting) and results with and without datum plane machining indicates an improvement (reduction) of the values characterizing the class of the tooth profile $\left(f_{H \alpha}, f_{f \alpha}\right.$ and $\left.F_{\alpha}\right)$, tooth line $\left(f_{f \beta}\right)$ and pitch $\left(f_{\text {pmax }}, f_{\text {umax }}\right)$. Since tooth line accuracy is outside the class, the entire gear falls outside the accuracy class 12. The tooth milling process keeps the gear within accuracy class 8 . The main reason is the high value of the greatest pitch interval deviation $\left(f_{\text {umax }}\right)$. Tooth profile and tooth line are significantly improved; in both cases, accuracy class 7 was achieved.

\subsection{An Analysis of the Accuracy of Tooth Geometric Surface Structure}

Selected surface and profile parameters were used for the evaluation of two-dimensional and threedimensional characterization of the surface structure 
and its directionality. Fig. 3 presents results obtained by means of the Talyscan 150 3D scanning instrument. Surfaces of the test samples were reviewed by analysing selected roughness parameters [23] or [24] shown in Tables 7 and 8.

The geometric structure of the surface after melting and sand-blasting can be described as nonoriented (random isotropic surface). Meanwhile, in the milled geometric surface structure, a periodic component - its presence related to traces left by individual mill bits - and a random component (mixed anisotropic surface) is manifested. $S q, S t$ amplitude parameters, in line with expectations, decrease with the application of sand-blasting and milling. Skew index $S s k$ and concentration index $S k u$ are sensitive to local hills or pits. The Ssk index for all test surfaces is very low; for negative values (fused surface), surfaces with rounded, plateau-like hills are indicated.
A positive Ssk value suggests sharp-edged hills (sandblasted and milled surfaces), although for the milled surface its value nears zero (0.00784). The Sku parameter value for all surfaces is close to 3 , which means that ordinate distribution approaches a normal distribution. For a fused surface, the $S k u$ parameter is 2.634 and displays lower concentrations than a normal distribution, while for a sand-blasted surface it shows greater concentrations (3.999).

The Abbott-Firestone bearing area curve (BAC) is most favourable for the milled surface, for which core roughness height $S k$ is $1.2034 \mu \mathrm{m}$, whereas reduced hill height $S p k$ and reduced pit depth $S v k$ have similar levels. Key 2D roughness parameters were specified in the direction perpendicular to the projected (theoretical) line of contact of gear teeth in meshing. After the sand-blasting process, the $R a$ parameter is 3.474, which complies to the $R a$ value specified by
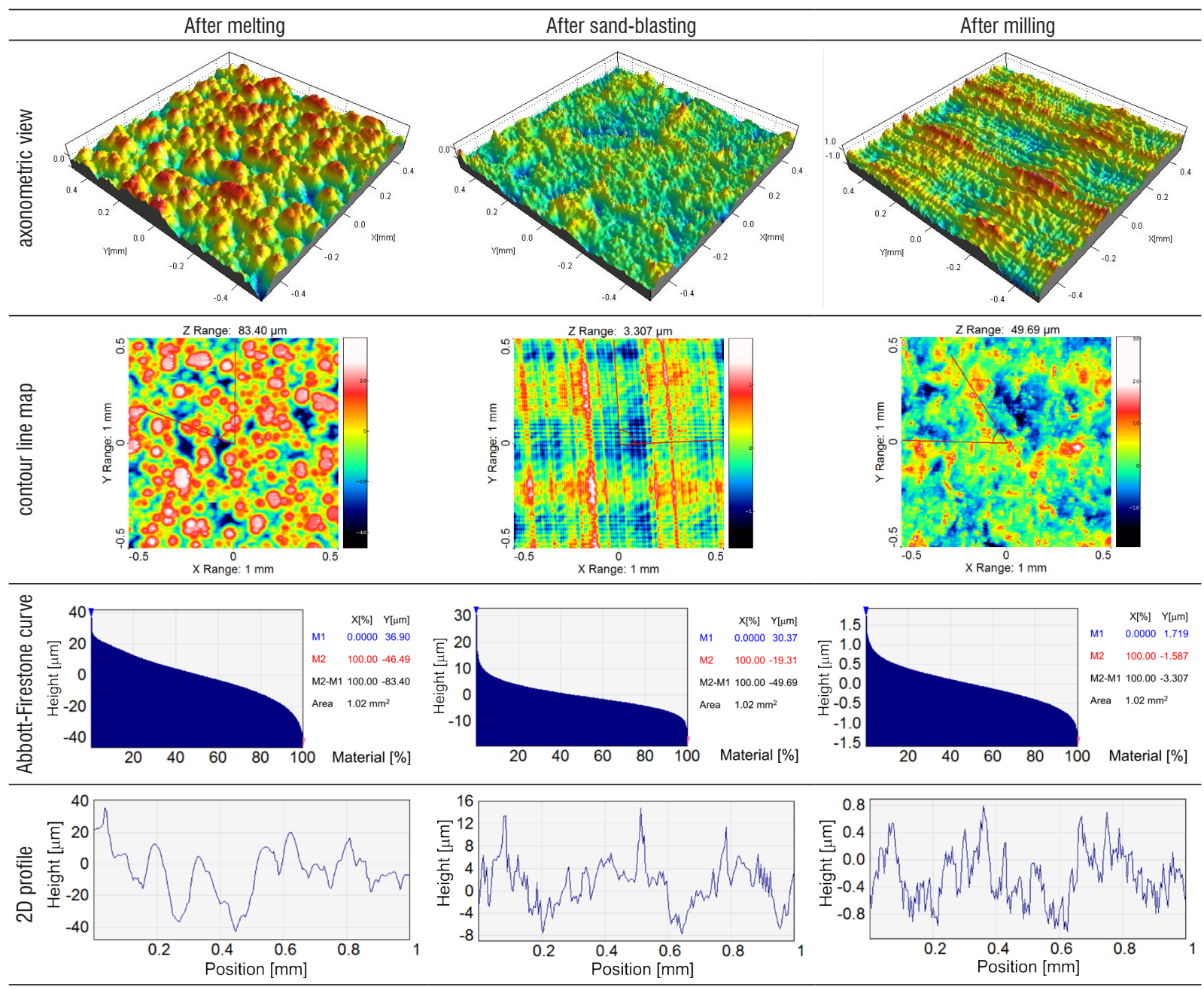

Fig. 3. Micro-geometry of test surfaces 
the manufacturer $(2.5 \mu \mathrm{m}$ to $4.5 \mu \mathrm{m})$. Likewise, the $R z$ parameter is contained within the range of $15 \mu \mathrm{m}$ to $40 \mu \mathrm{m}$ [16]. A satisfactory value of the $R a$ parameter $(0.387 \mu \mathrm{m})$ was obtained after milling, as it had been assumed that $R a$ for the tooth flank surface would be $1.6 \mu \mathrm{m}$. The distribution of profile ordinates reveals a concentration index $(R k u)$ of 2.3156 , which allows us to conclude that the distribution deviates from normal (i.e., is more flattened) and demonstrates left-sided asymmetry (most results above the mean), with the skewness index Rsk equal to -1.1516.

Table 7. Surface roughness parameters

\begin{tabular}{lccc}
\hline Parameters & $\begin{array}{c}\text { Surface after } \\
\text { printing }\end{array}$ & $\begin{array}{c}\text { Surface after } \\
\text { sanding }\end{array}$ & $\begin{array}{c}\text { Surface after } \\
\text { milling }\end{array}$ \\
\hline$S a[\mu \mathrm{m}]$ & 11.292 & 3.863 & 0.37097 \\
\hline$S q[\mu \mathrm{m}]$ & 13.931 & 4.9732 & 0.46429 \\
\hline$S s k[-]$ & -0.29245 & 0.47266 & 0.078346 \\
\hline$S k u[-]$ & 2.635 & 3.9992 & 2.95 \\
\hline$S p k[\mu \mathrm{m}]$ & 7.6112 & 7.2297 & 0.51499 \\
\hline$S k[\mu \mathrm{m}]$ & 36.797 & 11.775 & 1.2034 \\
\hline$S v k[\mu \mathrm{m}]$ & 14.133 & 3.9158 & 0.39615 \\
\hline$S z[\mu \mathrm{m}]$ & 83.397 & 49.687 & 3.3066 \\
\hline
\end{tabular}

Table 8. Profile roughness parameters

\begin{tabular}{lccc}
\hline Parameters & $\begin{array}{c}\text { Profile after } \\
\text { printing }\end{array}$ & $\begin{array}{c}\text { Profile after } \\
\text { sanding }\end{array}$ & $\begin{array}{c}\text { Profile after } \\
\text { milling }\end{array}$ \\
\hline$R a[\mu \mathrm{m}]$ & 12.478 & 3.475 & 0.38745 \\
\hline$R q[\mu \mathrm{m}]$ & 16.198 & 4.2962 & 0.46656 \\
\hline$R s k[-]$ & -1.0655 & 1.0232 & -1.1516 \\
\hline$R k u[-]$ & 3.1495 & 3.4612 & 2.3156 \\
\hline$R p k[\mu \mathrm{m}]$ & 27.167 & 10.681 & 0.51309 \\
\hline$R p[\mu \mathrm{m}]$ & 35.7 & 14.799 & 0.78726 \\
\hline$R v[\mu \mathrm{m}]$ & 42.879 & 7.7116 & 1.0655 \\
\hline$R z[\mu \mathrm{m}]$ & 78.579 & 22.51 & 1.8527 \\
\hline
\end{tabular}

\section{CONCLUSIONS}

Due to the complexity of the DMLS process, the correct use of workpieces depends on the knowledge of materials used in the process as well as mechanisms at work during the melting process. Correct model fabrication means the most accurate real-time geometry in reference to the geometry of the CAD model. To achieve this, the following conditions must be satisfied:

- correct data processing (selection of export parameters of models to STL format);

- correct preparation of the manufacturing process (e.g., generating anchoring structures);
- correct positioning of the component to be produced in the machine's workspace;

- allowances for post-processing operations.

In the analysed case of a spur gear, the application of the machining process, i.e., turning datum planes of the gear blank, gave appropriate results. The results obtained from measuring the gears after the melting process with datum reference machining were more accurate than the results obtained from the measurement of gears without datum reference machining. This is due to the form deviation of the datum surfaces. For both cases, after the melting process, the gears are outside accuracy class 12 according to DIN 3962. A similar conclusion may be drawn for the gear tooth milling process using a universal tool, which in this case was an end mill. This solution helps achieve gear accuracy class 8 . It may be supposed that the application of specialist tooth machining tools, used in generating or profiling, should yield even a higher accuracy class. To fully evaluate the workability of the GP1 material, gear teeth must be tested after a corresponding heat treatment followed by grinding.

As expected, the parameters that characterize the geometric structure of the surface after tooth milling are reduced by $96.8 \%$ in comparison to parameters obtained following the melting process. $R a$ profile parameter of $12.5 \mu \mathrm{m}$ was reduced to $0.4 \mu \mathrm{m}$.

Sand-blasting helps achieve a far superior tooth surface geometry structure compared to the surface after printing, but it fails to significantly upgrade gear accuracy class.

Tooth measurements on a coordinate measuring machine after melting and sand-blasting demonstrated that the profile angle for the right- and left-hand sides is lower than assumed for the model (negative deviation of profile position). It can be caused by shrinkage of the material. Surface topography, not shown in this study, confirms the consistency of profile angle position deviation along the width of the ring. Moreover, cylindrical surface measurements on the gear's blank indicate that such surfaces are in fact elliptical. It was also observed that the shape deviations became larger with increasing distance of the workpiece from the central position on the building platform.

Manufacturing cost and time in additive methods often differ from those characterizing conventional manufacturing approaches. This is due to the specifics of additive manufacturing. In the analysed case, the manufacturing time for a gear wheel made by means of DMLS is ten times longer than that of manufacturing a single gear from full material. Meanwhile, the cost of 
manufacturing is over ten times higher than the cost of fabricating the same gear using conventional methods. The main cost drivers in the DMLS include materials, manufacturing, machine depreciation and labour. In spite of a preliminary gear wheel design, some postprocessing is required, which significantly impacts part fabrication time and costs. Please note, however, that the analysed manufacturing method is far from inexpensive, but its cost-effectiveness increases with the complexity of the shape to be obtained [25]. The DMLS sintering process with appropriately selected parameters could be an alternative for manufacturing soft cylindrical gears in single-piece and smallvolume production.

In further work, the authors intend to study the effect of gear positioning across the building platform on tooth strength.

\section{REFERENCES}

[1] Bremen, S., Meiners, W., Diatlov, A. (2012) Selective laser melting. A manufacturing technology for the future? Laser Technik Journal, vol. 9, no. 2, p. 33-38, D0l:10.1002/ latj.201290018.

[2] Rontescu, C., Pacioga, A., lacobescu, G., Amza, C.-G. (2016). Research on the mechanical properties of titanium biocompatible alloys obtained by sintering. U.P.B. Scientific Bulletin, Series B: Chemistry and Material Science, vol. 78, no. 2, 195-202.

[3] Mower, T.M., Long, M.J. (2016). Mechanical behavior of additive manufactured, powder-bed laser-fused materials. Materials Science and Engineering: A, vol. 651, p. 198-213, DOI:10.1016/j.msea.2015.10.068.

[4] Manfredi, D., Calignano, F., Krishnan, M., Canali, R., Ambrosio E.P., Atzeni, E. (2013). From powders to dense metal parts: Characterization of a commercial AlSiMg alloy processed through direct metal laser sintering. Materials, vol. 6, no. 3, p. 856-869, D0I:10.3390/ma6030856.

[5] Zhang, J., Zhang, Y., Guo, X., Lee, W. H., Hu, B., Lu, Z., Jung, Y.-G., Lee, H. (2016). Characterization of microstructure and mechanical properties of direct metal laser sintered 15-5 Ph1 stainless steel powders and components. 145th Annual Meeting \& Exhibition: Supplemental Proceedings John Wiley \& Sons, Inc., Hoboken, Dol:10.1002/9781119274896.ch2.

[6] Simchi, A. (2006). Direct laser sintering of metal powders: Mechanism, kinetics and microstructural features. Materials Science and Engineering: A, vol. 428, no. 1-2, p. 148-158, DOl:10.1016/j.msea.2006.04.117.

[7] Zhang, Y., Zhang, J. (2016). Sintering phenomena and mechanical strength of nickel based materials in direct metal laser sintering process - A molecular dynamics study. Journal of Materials Research, vol. 31, no. 15, p. 2233-2243, DOI:10.1557/jmr.2016.230.

[8] Ghosh, S.K., Saha, P. (2011). Crack and wear behavior of SiC particulate reinforced aluminium based metal matrix composite fabricated by direct metal laser sintering process.
Materials \& Design, vol. 32, no. 1, p. 139-145, Dol:10.1016/j. matdes.2010.06.020.

[9] Grünberger, T., Domröse, R. (2015). Direct metal laser sintering - Identification of process phenomena by optical inprocess monitoring. Laser Technik Journal, vol. 12, no. 1, p. 45-48, DOl:10.1002/latj.201500007.

[10] Simchi, A., Petzoldt, F., Pohl, H. (2003). On the development of direct metal laser sintering for rapid tooling. Journal of Materials Processing Technology, vol. 141, no. 3, p. 319-328, DOl:10.1016/S0924-0136(03)00283-8.

[11] Bertol, L.S., Kindlein Júnior, W., da Silva, F.P., Aumund-Kopp, C. (2010). Medical design: Direct metal laser sintering of Ti6Al-4V. Materials \& Design, vol. 31, no. 8, p. 3982-3988, DOl:10.1016/j.matdes.2010.02.050.

[12] Traini, T., Mangano, C., Sammons, R.L., Mangano, F., Macchi, A., Piattelli, A. (2008). Direct laser metal sintering as a new approach to fabrication of an isoelastic functionally graded material for manufacture of porous titanium dental implants. Dental Materials, vol. 24, no. 11, p. 1525-1533, DOl:10.1016/j.dental.2008.03.029.

[13] Mangano, F., Chambrone, L., van Noort, R., Miller, C., Hatton, P., Mangano, C. (2014). Direct metal laser sintering titanium dental implants: A review of the current literature. International Journal of Biomaterials, vol. 2014, art. ID 461534, p. 1-11, DOl:10.1155/2014/461534.

[14] Radzevich, S.P. (2012). Dudley's Handbook of Practical Gear Design and Manufacture, $2^{\text {nd }}$ Ed., CRC Press, Boca Raton, Dol:10.1201/b11842.

[15] Kruth, J-P., Mercelis, P., Van Vaerenbergh, J., Froyen, L., Rombouts, M. (2005). Binding mechanisms in selective laser sintering and selective laser melting. Rapid Prototyping Journal, vol. 11, no. 1, p. 26-36, Dol:10.1108/13552540510573365.

[16] EOS GmbH (2016). Electro Optical Systems from http://www. eos.info/, accessed on 2016-09-25.

[17] Dziubek, T., Pisula, J. (2013) Analysis of the accuracy of the 3D-CAD model of cylindrical gear obtained by the machining simulation for parametric surface models. Mechanik, no. 2, p. 1-12. (in Polish)

[18] Nelik, L. (1999). Centrifugal and Rotary Pumps: Fundamentals with Applications. CRC Press, Boca Raton, DOI:10.1201/9781420049725.

[19] Batsch, M., Pisula J., Przeszłowski, J., Bernaczek J. (2016). Tests and analyses of variants of a scraper with an integrated planetary gearing. Report No. 3 from studies carried out as part of project "Development of an Innovative Type of a Scraper with an Integrated Planetary Drive for New or Modernized Sedimentation Tanks" (POIR.01.01.01-000286/15-00).

[20] Bagci E., Yüncüoğlu E.U. (2017). The effects of milling strategies on forces, material removal rate, tool deflection, and surface errors for the rough machining of complex surfaces. Strojniški vestnik - Journal of Mechanical Engineering, vol. 63, no. 11, p. 643-656, D0I:10.5545/sv-jme.2017.4450.

[21] DIN 3962-1,2 (1978). Tolerances for cylindrical gear teeth. Part 1: Tolerances for deviations of individual parameters. Part 2: Tolerances for tooth trace deviation. Deutsches Institut für Normung, Frankfurt am Main. 
[22] Oczos, K.E., Lubimov, V. (2003). Geometrical surface structure product specifications. Basis of classification including an atlas of characteristic shaped surfaces. Rzeszow University of Technology Publishing House, Rzeszow (in Polish).

[23] ISO/DIS 25178-2:2012. Geometrical product specifications (GPS) - Surface texture: Areal - Part 2: Terms, definitions and surface texture parameters. The International Organization for Standardization, Geneva.

[24] Atzeni, E., Salmi, A. (2012). Economics of additive manufacturing for end-usable metal parts. The International Journal of Advanced Manufacturing Technology, vol. 62, no. 9-12, p. 1147-1155, Dol:10.1007/s00170-011-3878-1. 